\title{
A Study on Strengthening of CHS Tubes under Axial Compression Using FRP Composites
}

\author{
Iyappan. G. R \\ Assistant Professor \\ Department of Civil Engineering \\ Valliammai Engineering College \\ Kattankulathur. India
}

\author{
Dr. D. Elango \\ Professor\& Head \\ Department of Civil Engineering \\ Valliammai Engineering College \\ Kattankulathur. India
}

\begin{abstract}
External bonding of Glass fiber reinforced polymer (GFRP) sheets to the periphery of steel circular hollow sections (CHS) is a new technique for structurally improving such sections. This paper involves in analyzing the capacity of GFRP-strengthened steel CHS tubes subjected to bending. The main aim of wrapping GFRP sheets is to reduce the buckling behavior of CHS. Design of GFRP sheets for strengthening tubular steel sections necessitates the prediction of the capacity of confined steel circular sections. This paper presents a design method for evaluating the capacity of GFRP-strengthened steel CHS subjected to bending. The hoop FRP reduces the effect of local buckling by restraining the tube wall. The influence of hoop CFRP is considered in the proposed method by taking its modulus of elasticity as a proportion of the elastic modulus of longitudinal GFRP. The excitation of the longitudinal GFRP minimizes the effect of local buckling in the tube wall, which ultimately increases the local flexural stiffness and strength of the tube.
\end{abstract}

Keywords: Concrete, Compressive strength, Glass Fiber Reinforcing Polymer, Circular Hollow Steel.

\section{INTRODUCTION}

Steel sections are very much usage in most of the structures. Especially circular hollow section. A hollow structural section (HSS) is a type of metal profile with a hollow tubular cross section. The term is used predominantly in USA, or other countries which follow US construction or engineering terminology.

HSS members can be circular, square, or rectangular sections, although other shapes are available, such as elliptical. HSS is only composed of structural steel per code.HSS is sometimes mistakenly referenced as hollow structural steel. Rectangular and square HSS are also commonly called tube steel or structural tubing. Circular HSS are sometimes mistakenly called steel pipe though true steel pipe is actually dimensioned and classed differently from HSS. (HSS dimensions are based on exterior dimensions of the profile, while pipes are essentially dimensioned based on interior diameters, as needed to calculate areas for flow of liquids.) The corners of HSS are heavily rounded, having a radius which is approximately twice the wall thickness. The wall thickness is uniform around the section. In the UK, or other countries which follow British construction or engineering terminology, the term HSS is not used. Rather, the three basic shapes are referenced as CHS, SHS, and RHS, being circular, square, and rectangular hollow sections. Typically, these designations will also relate to metric sizes, thus the dimensions and tolerances differ slightly from HSS.

HSS, especially rectangular sections, are commonly used in welded steel frames where members experience loading in multiple directions. Square and circular HSS have very efficient shapes for this multiple-axis loading as they have uniform geometry along two or more cross-sectional axes, and thus uniform strength characteristics. This makes them good choices for columns. They also have excellent resistance totorsion.HSS can also be used as beams, although wide flange or I-beam shapes are in many cases a more efficient structural shape for this application.

\section{Methodology}

\subsection{Cement}

The most common cement used is an ordinary Portland cement. The Ordinary Portland Cement of 53 grades conforming to IS: 11269-1987 isbe use. Many tests were conducted on cement; some of them are consistency tests, setting tests, soundness tests, etc. 
Iyappan. G. R \& Dr. D. Elango

Table1. Properties of Cement

\begin{tabular}{|c|c|c|c|}
\hline $\begin{array}{c}\text { Sr. } \\
\text { No. }\end{array}$ & $\begin{array}{c}\text { Physical Properties of } \\
\text { OPC 53Cement }\end{array}$ & Results & $\begin{array}{c}\text { Requirements as Per } \\
\text { IS:8112-1989 }\end{array}$ \\
\hline 1. & Specific Gravity & 3.14 & $3.10-3.15$ \\
\hline 2. & Standard Consistency (\%) & 31.5 & $30-35$ \\
\hline 3. & Initial Setting Time (min) & 30 & 60 Minimum \\
\hline 4. & Final Setting Time (min) & 211 & 600 Maximum \\
\hline 5. & $\begin{array}{c}\text { Compressive Strength } \\
\text { (at } 28 \text { days in N/mm }{ }^{2} \text { ) }\end{array}$ & 58 & 53 Minimum \\
\hline
\end{tabular}

\subsection{Aggregate}

Aggregates are the important and large used constituents in concrete. They give bond to the concrete, reduce shrinkage and effect economy. One of the most important factors for producing workable concrete is good gradation of aggregates. Many tests were conducted on fine aggregate and coarse aggregate are tabulated below. The test results in Fine and coarse aggregate are conforming to IS: 383-1970.

Table2. Physical Properties of Fine and Coarse Aggregate

\begin{tabular}{|c|c|c|}
\hline Particular & Fine aggregate & Coarse aggregate \\
\hline Specific gravity & 2.68 & 2.73 \\
\hline Water absorption (\%) & 1 & 0.5 \\
\hline Fineness modulus & 2.72 & 7.32 \\
\hline Bulk density (g/cc) & 1.43 & - \\
\hline Percentage of voids & 43.29 & - \\
\hline Grading & Zone II & - \\
\hline
\end{tabular}

\subsection{Hollow Steel Section}

Square HSS is made the same way as pipe. During the manufacturing process flat steel plate is gradually changed in shape to become round where the edges are presented ready to weld. The edges are then welded together to form the mother tube. During the manufacturing process the mother tube goes through a series of shaping stands which form the round HSS (mother tube) into the final square or rectangular shape. Most American manufacturers adhere to the ASTM A500 or newly adopted ASTM A1085 standards, while Canadian manufacturers follow both ASTM A500 and CSA G40.21. European hollow sections are generally in accordance with the EN 10210 standard.

In this project investigation is done with American standard CS 50 steel tubes made in fabrication plant.

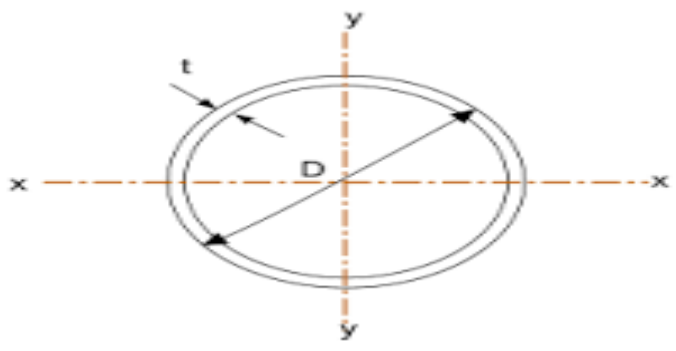

Figure1. Diameter of circular hollow section

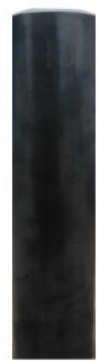

Figure2. Circular hollow steel tubes 


\subsection{GFRP (Glass Fiber Reinforcing Polymer)}

Glass fiber-reinforced polymer, carbon fiber-reinforced plastic or carbon fiber-reinforced thermoplastic (GFRP, often simply glass fiber, or even carbon), is an extremely strong and light fiberreinforced plastic which contains glass fibers. CFRPs can be expensive to produce but are commonly used wherever high strength-to-weight ratio and rigidity are required, such as aerospace, automotive and civil engineering, sports goods and an increasing number of other consumer and technical applications.

Table3. Properties of GFRP sheet

\begin{tabular}{|c|c|}
\hline Particular & \\
\hline Fiber Orientation & Unidirectional \\
\hline Weight $\left(\mathrm{g} / \mathrm{m}^{2}\right)$ & 200 \\
\hline Density $(\mathrm{g} / \mathrm{cc})$ & 2.6 \\
\hline Thickness $(\mathrm{mm})$ & 0.40 \\
\hline Ultimate elongation $(\%)$ & 1.5 \\
\hline Tensile strength $\left(\mathrm{N} / \mathrm{mm}^{2}\right)$ & 3500 \\
\hline Tensile modulus $\left(\mathrm{N} / \mathrm{mm}^{2}\right)$ & $285 \times 10^{3}$ \\
\hline
\end{tabular}

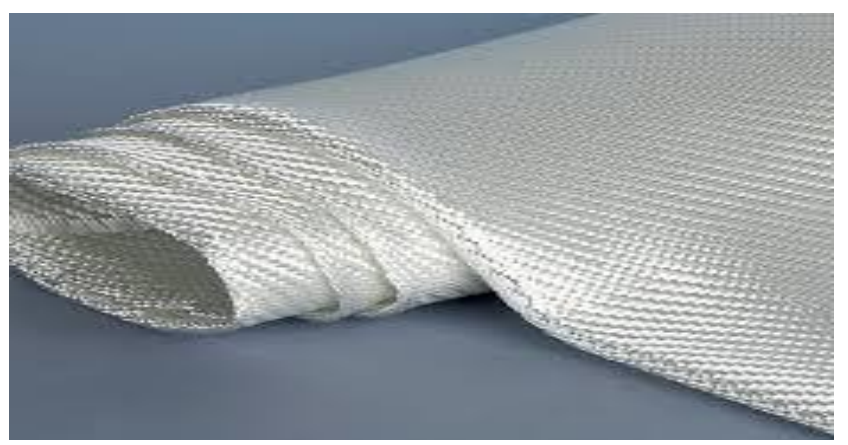

Figure3. GFRP Sheet

\subsection{Mix Design}

The mix proportion chosen for this study is M25 grade (1:2.01:3.56) with water-cement ratio of 0.45 . Cubes of standard size $150 \times 150 \times 150 \mathrm{~mm}$ of total 36 no. are casted and cured for 28 days and tested as per code IS: 516-1959.

Table4. Mix proportion for M25 Grade Concrete

\begin{tabular}{|l|l|l|l|l|l|}
\hline Unit of batch & Water (liter) & Cement $(\mathbf{k g})$ & Sand $(\mathbf{k g})$ & $\begin{array}{l}\text { Coarse aggregate } \\
(\mathbf{k g})\end{array}$ & $\begin{array}{l}\text { Super } \\
\text { plasticizer }\end{array}$ \\
\hline $\begin{array}{l}\text { Meter cube } \\
\text { content }\end{array}$ & 164 & 375 & 375 & 750 & 3.75 \\
\hline Mix ratio & 0.45 & 1 & 1 & 2 & $1 \%$ \\
\hline
\end{tabular}

\section{RESULT AND DISCUSSION}

\subsection{Compressive Strength Test}

For compressive strength of concrete, a standard dimension of $150 \mathrm{~mm}$ x $150 \mathrm{~mm}$ x $150 \mathrm{~mm}$ cubes were used. Compressive strength results consist for M25 grade of concrete with maintain constant $\mathrm{W} / \mathrm{C}$ ratio of 0.45 . The compressive test is done after the specimen has been cured for 14 and 28 days. All the cubes were tested in saturated condition, after wiping out the moisture in their surface.

The compressive test is done in compressive testing machine has the capacity of $1000 \mathrm{KN}$. The compressive strength test is carried out on various specimen like control specimen $(\mathrm{C} 0)$, warping GFRP sheet in one layer (C1), two layer (C2), three layer (C3) in control specimen. For each specimen was tested in 3 trials.

Compression test was carried out on the specimens on $7^{\text {th, } 14 \text { th }}$ and $28^{\text {thdays }}$ of curing and the values are tabulated. The compressive strength also calculated and given. In fig 5, the block color values indicate compressive strength of $\mathrm{C} 3$ (three layer warping in control specimen). Loading was continued till the readings were revised from the increment values. 
The reversal in the reading value indicates the specimen has failed. The machine was stopped and the reading at that instant was the ultimate load. The ultimate load divided by the cross sectional area is the compressive strength.

Compressive strength $=\mathrm{P} / \mathrm{A}\left(\mathrm{N} / \mathrm{mm}^{2}\right)$

Where, $\mathrm{P}=\operatorname{Load}\left(\mathrm{N} / \mathrm{mm}^{2}\right)$

$\mathrm{A}=$ Area of the cube $=\mathrm{Lxb}$

Table5. Compressive strength test results for GFRP

\begin{tabular}{|c|c|c|}
\hline SL.NO & SPECIMEN & $\begin{array}{c}\text { 28 DAYS compressive Strength } \\
\left.\mathbf{( N / m m}^{\mathbf{2}}\right)\end{array}$ \\
\hline $\mathbf{1}$ & Control specimen & 31.2 \\
\hline $\mathbf{2}$ & One layer of GFRP & 31.8 \\
\hline $\mathbf{3}$ & Second layer of GFRP & 32.5 \\
\hline $\mathbf{4}$ & Third layer of GFRP & 33.8 \\
\hline
\end{tabular}

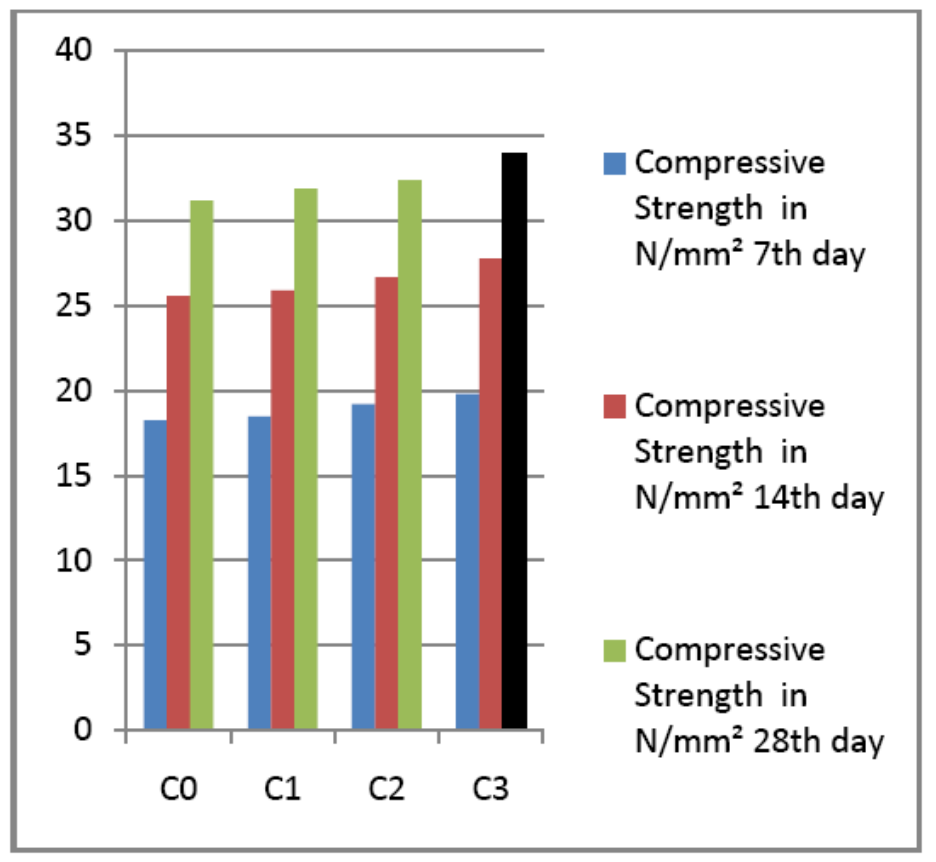

Figure5. Compressive Strength results for GFRP

\subsection{Flexural Strength}

Flexural strength is one measure of the tensile strength of concrete. It is a measure of an unreinforced concrete beam or slab to resist failure in bending. It is measured by loading 6 x 6 -inch $(150 \times 150$ $\mathrm{mm}$ ) concrete beams with a span length at least three times the depth. The flexural strength is expressed as Modulus of Rupture (MR) in psi (MPa) and is determined by standard test methods ASTM C 78 (third-point loading) or ASTM C 293 (center-point loading).Flexural MR is about 10 to 20 percent of compressive strength depending on the type, size and volume of coarse aggregate used. However, the best correlation for specific materials is obtained by laboratory tests for given materials and mix design.

In this paper mainly investigate flexural strength of the beam (vertical member) consists of with and without fibers. The circular steel tube made with fiber by using epoxy adhesive. For this test involves standard steel tube with in filled concrete (control specimen- without fiber), withfiber in 1 layer (CFCT-1), 2 layer (CFCT-2), 3 layer (CFCT-3).For each specimen was tested in 2 trials. The flexural test is done in the loading frame it has the capacity of $1500 \mathrm{KN}$. All the beams were tested in single point loading (@ center). The load is acted at the center of the beam. The dial gauges were used to find the deflection acting on the beam. For finding the load is given to the beam through the proving ring.

The dial gauge readings were recorded at different loads. The load was applied gradually until the first crack was observed. Subsequently, the load was applied. The behavior of the beam was observed 
carefully. The crack development and propagation were monitored and marked during progress of the test. The crack width was measured. The deflection was recorded for respective load increments until failure.

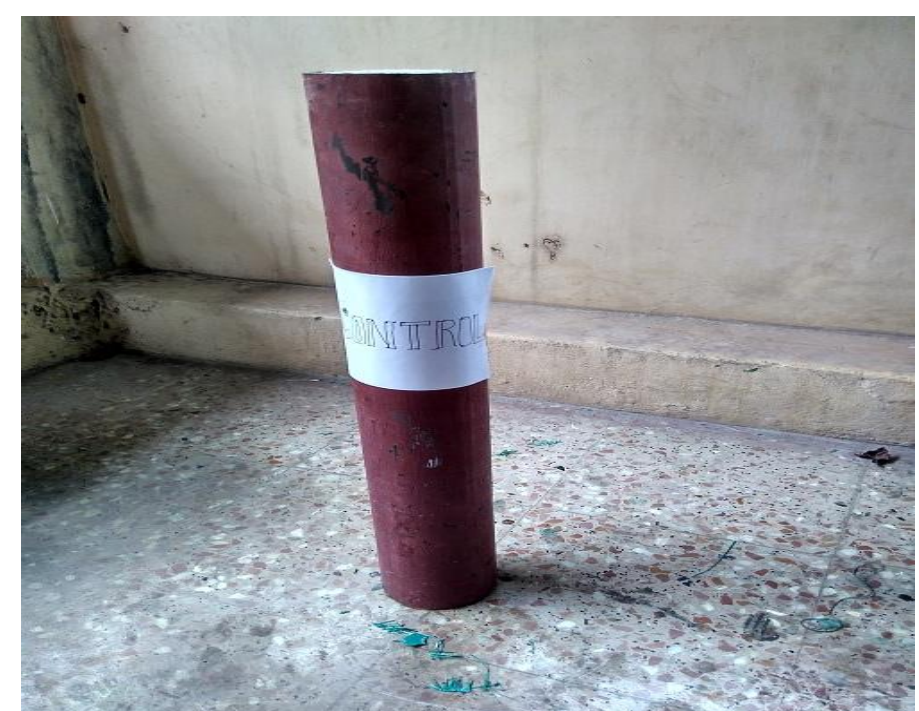

Figure6. Control specimen

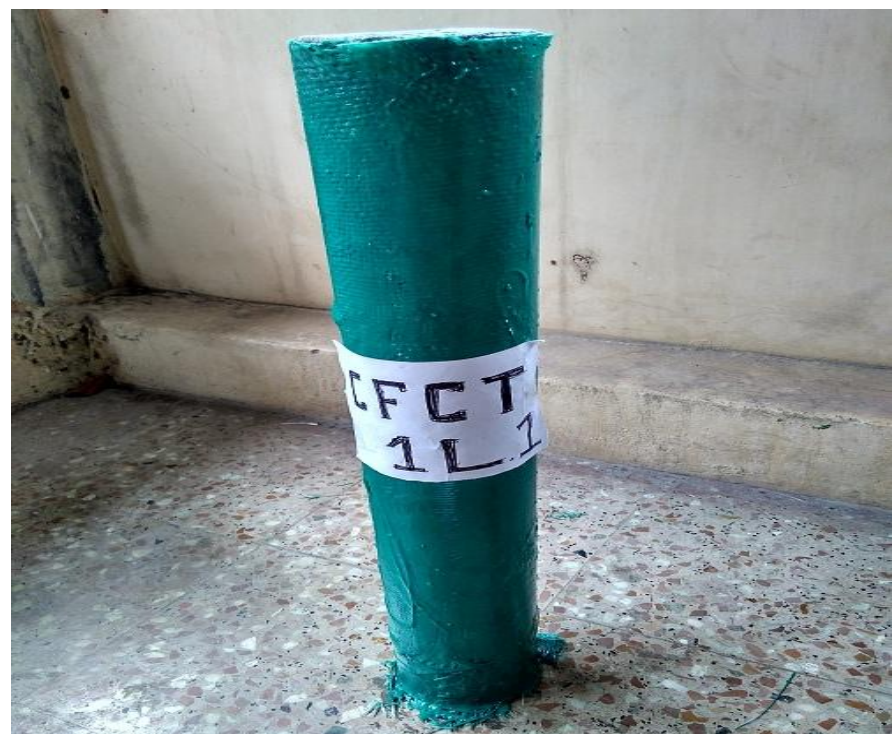

Figure7. First layer of CFCT specimen

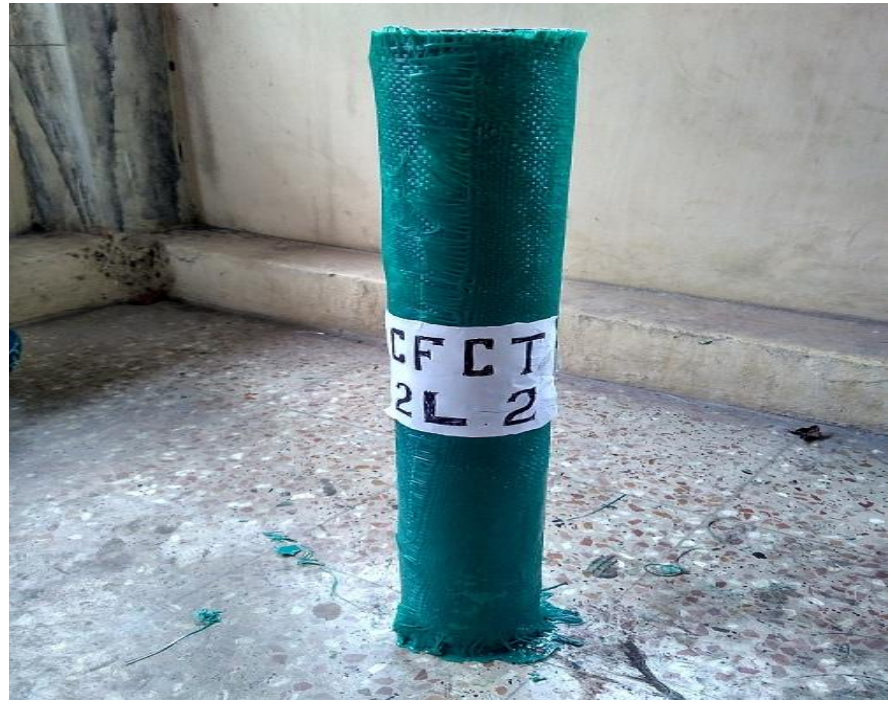

Figure8. Second layer of CFCT specimen 


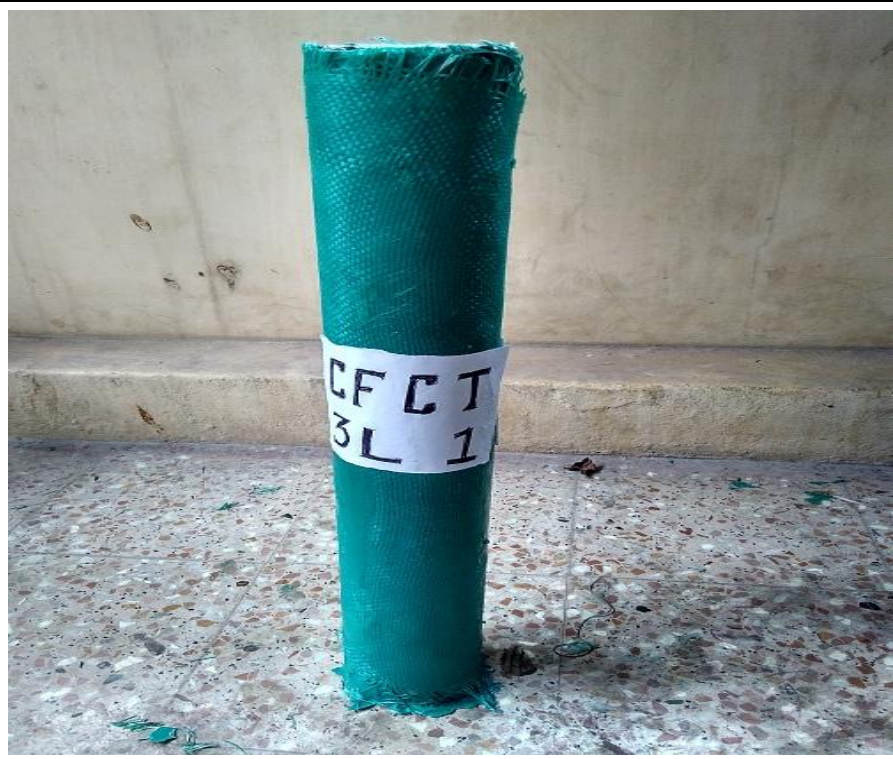

Figure9. Third layer of CFCT specimen

\subsection{Testing Results of Specimens Obtained From UTM}

Load and buckling behaviors are obtained for Control, CFCT- ${ }^{\text {st }}$ LAYER, CFCT- $2^{\text {nd }}$ LAYER, CFCT$3^{\text {rd }}$ LAYER, by experimentally testing the specimen in UTM. Evaluation of load and displacement for CFCT- ${ }^{\text {st }}$ LAYER, CFCT- $2^{\text {nd }}$ LAYER, and CFCT $-3^{\text {rd }}$ LAYER are presented below.

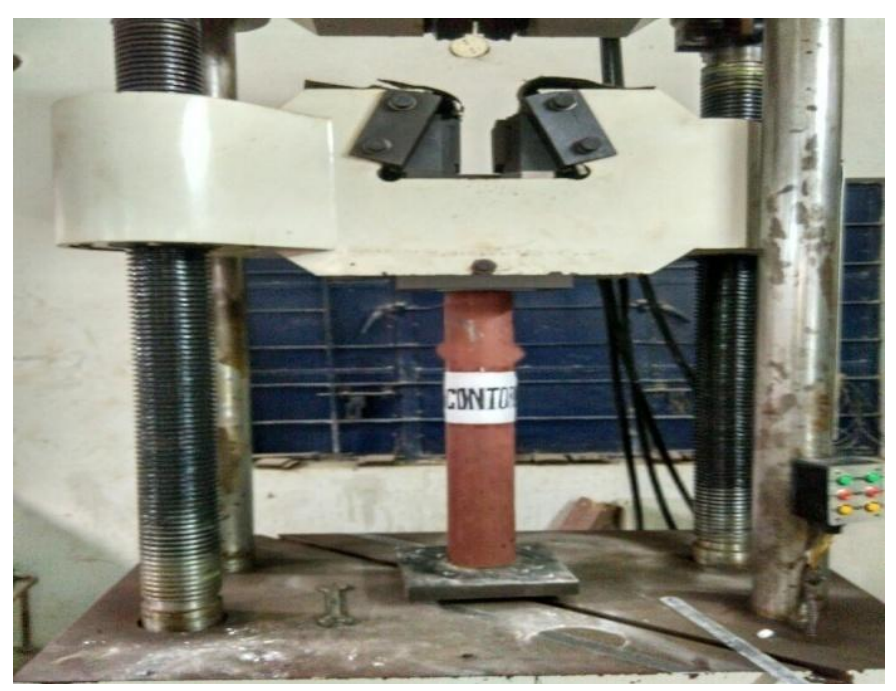

Figure10. Failure for control specimen

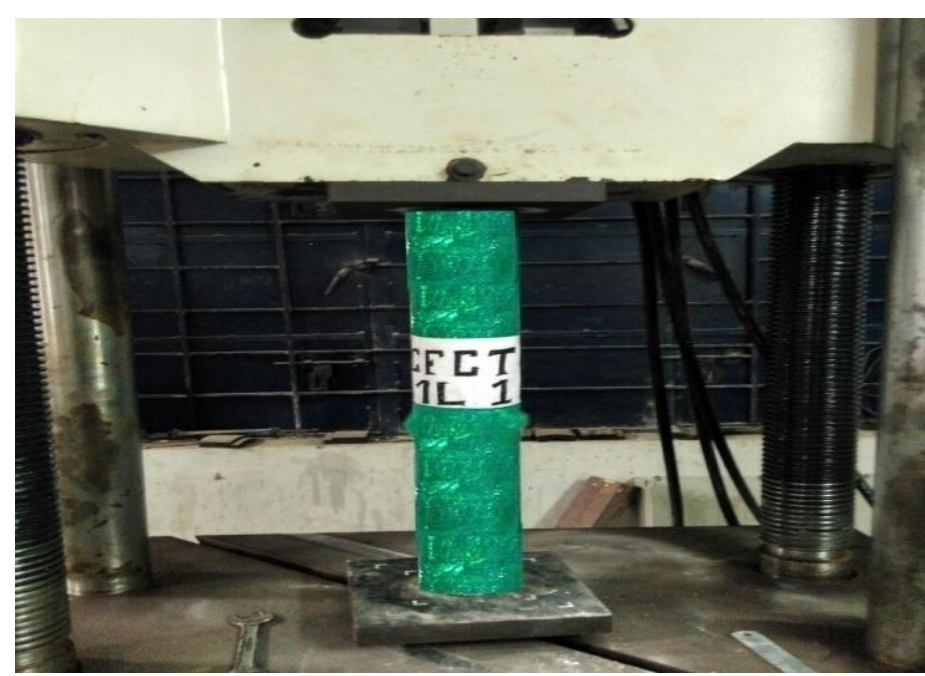

Figure11. Failure for First layer of CFCT specimen 


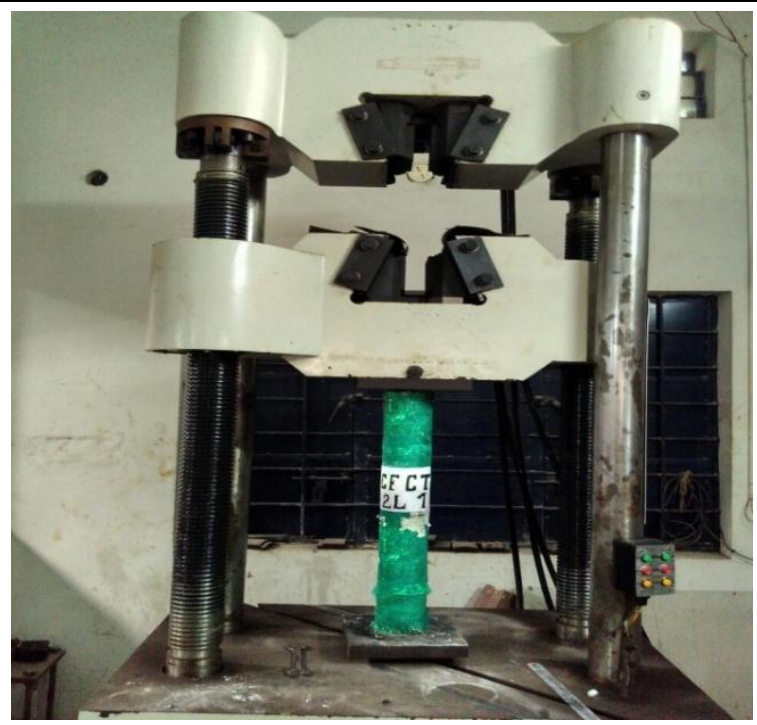

Figure12. Failure for Second layer of CFCT specimen

Table4. Load and Deflection

\begin{tabular}{|c|c|c|c|c|}
\hline \multirow{2}{*}{ Designation } & \multicolumn{2}{|c|}{ Load $(\mathbf{k N})$} & \multicolumn{2}{c|}{ Deflection $(\mathbf{m m})$} \\
\cline { 2 - 5 } & Trial 1 & Trial 2 & Trial 1 & Trial 2 \\
\hline Control & 940 & 932 & 11.63 & 12.07 \\
\hline CFCT (LAYER-I) & 1070 & 1100 & 12.31 & 12.98 \\
\hline CFCT (LAYER-II) & 1132 & 1126 & 11.84 & 12.37 \\
\hline CFCT (LAYER-III) & 1192 & 1148 & 11.79 & 11.23 \\
\hline
\end{tabular}

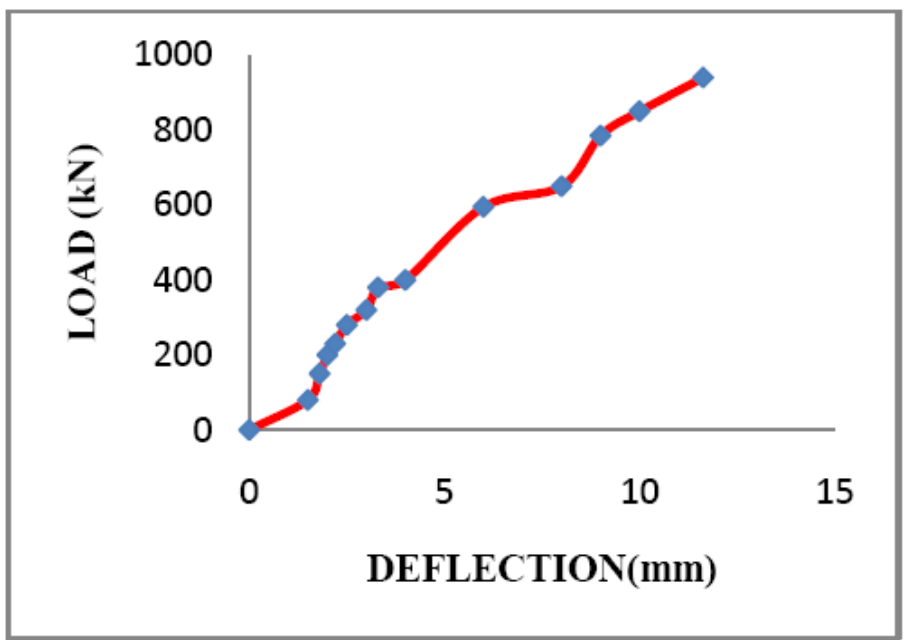

Figure13. Load Vs Deflection for Control specimen-I

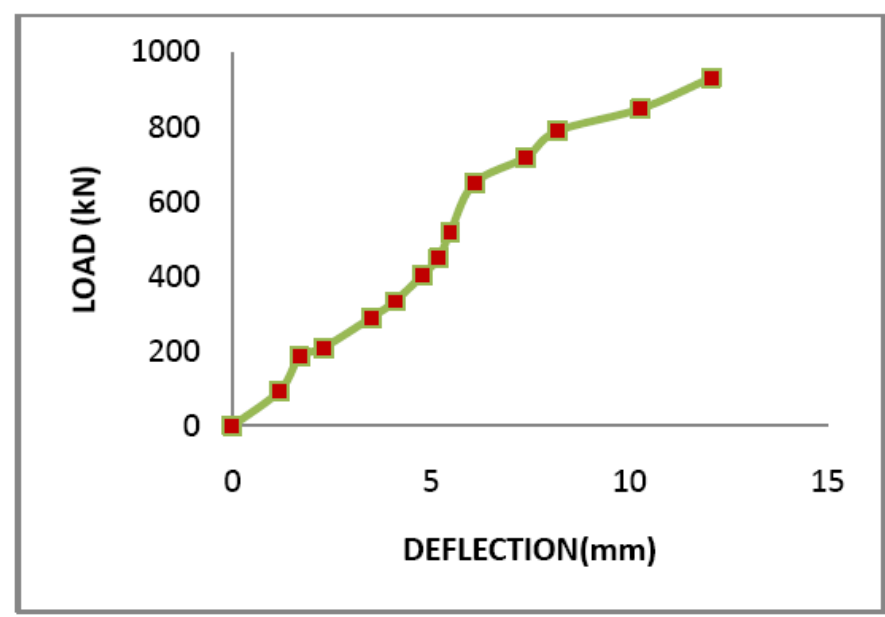

Figure14. Load Vs Deflection for Control specimen-II 


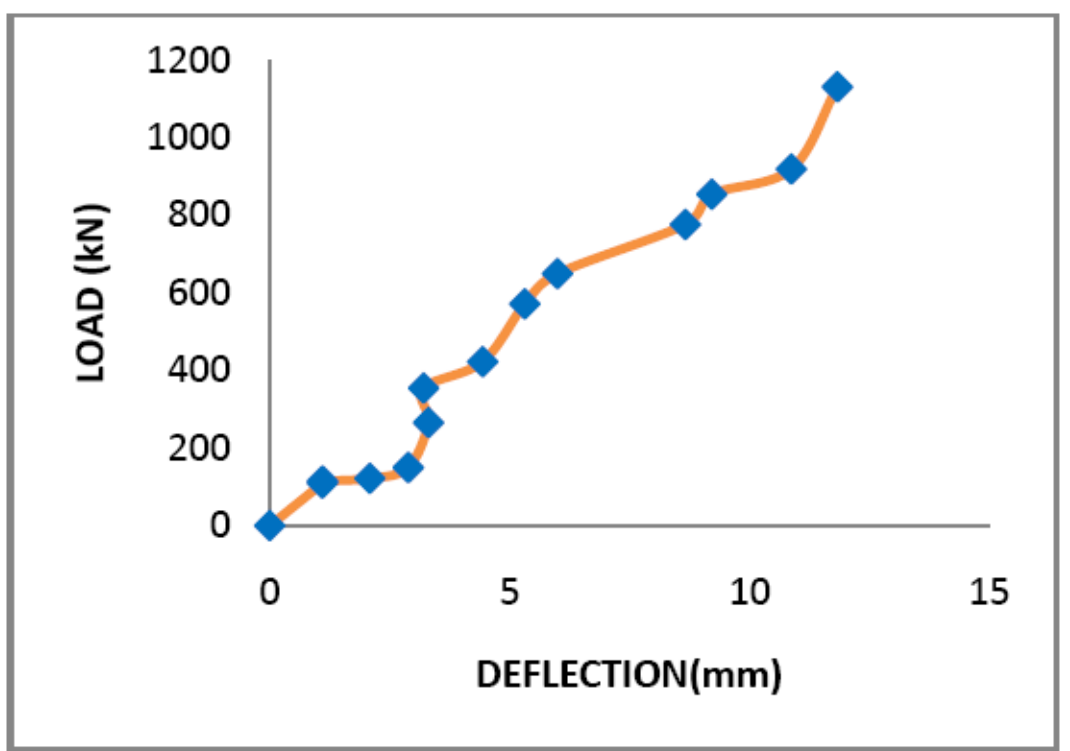

Figure15. Load Vs Deflection for First Layer CFCT -I

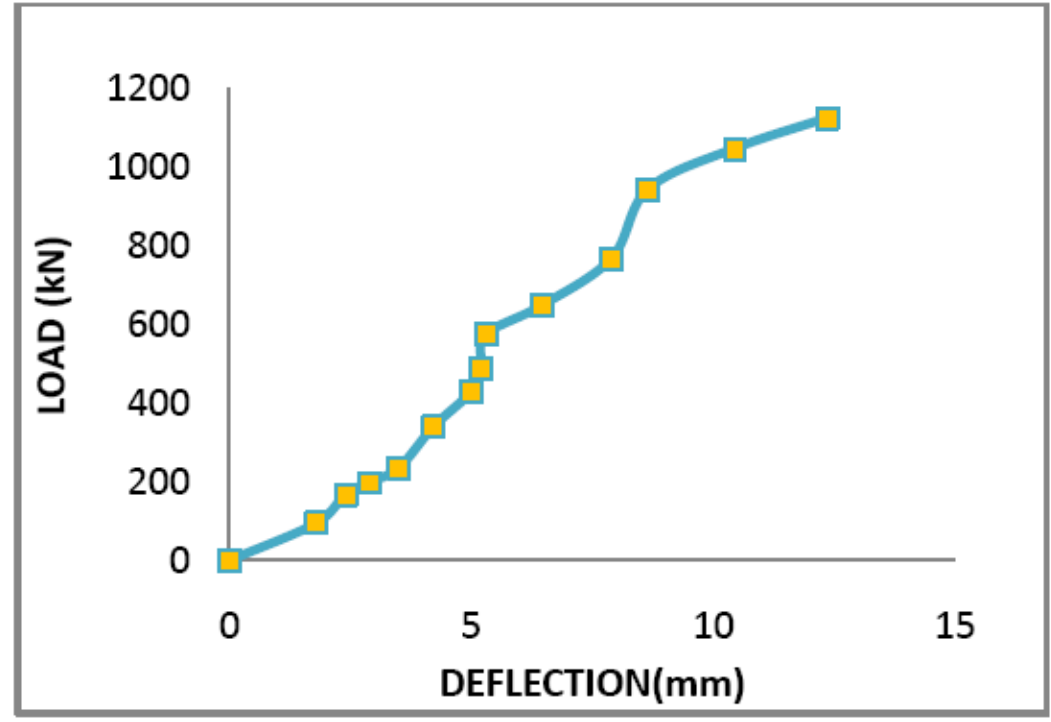

Figure16: Load Vs Deflection for First Layer CFCT -II

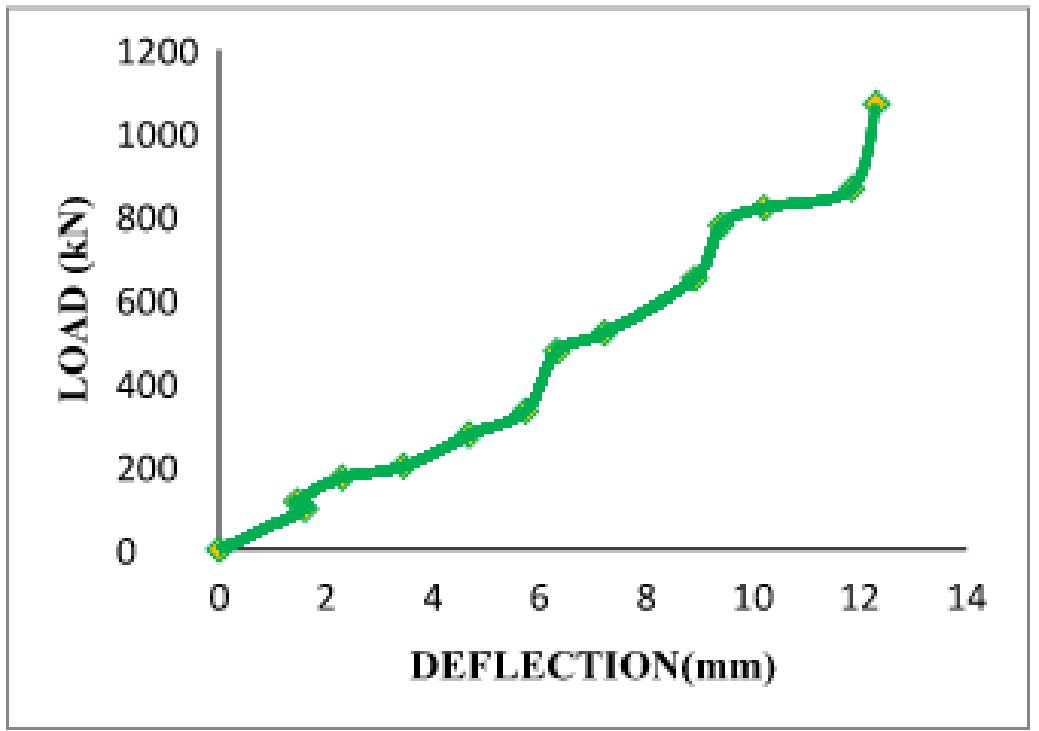

Figure17. Load Vs Deflection for Second Layer CFCT -I 


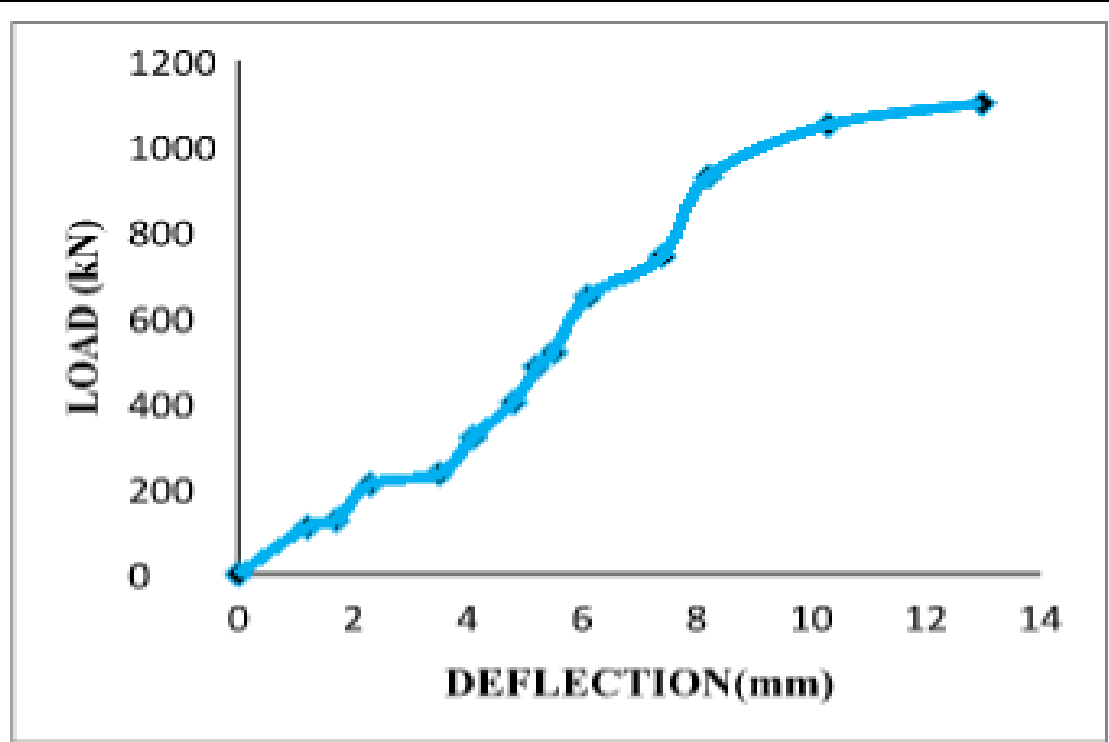

Figure18. Load Vs Deflection for Second Layer CFCT -II

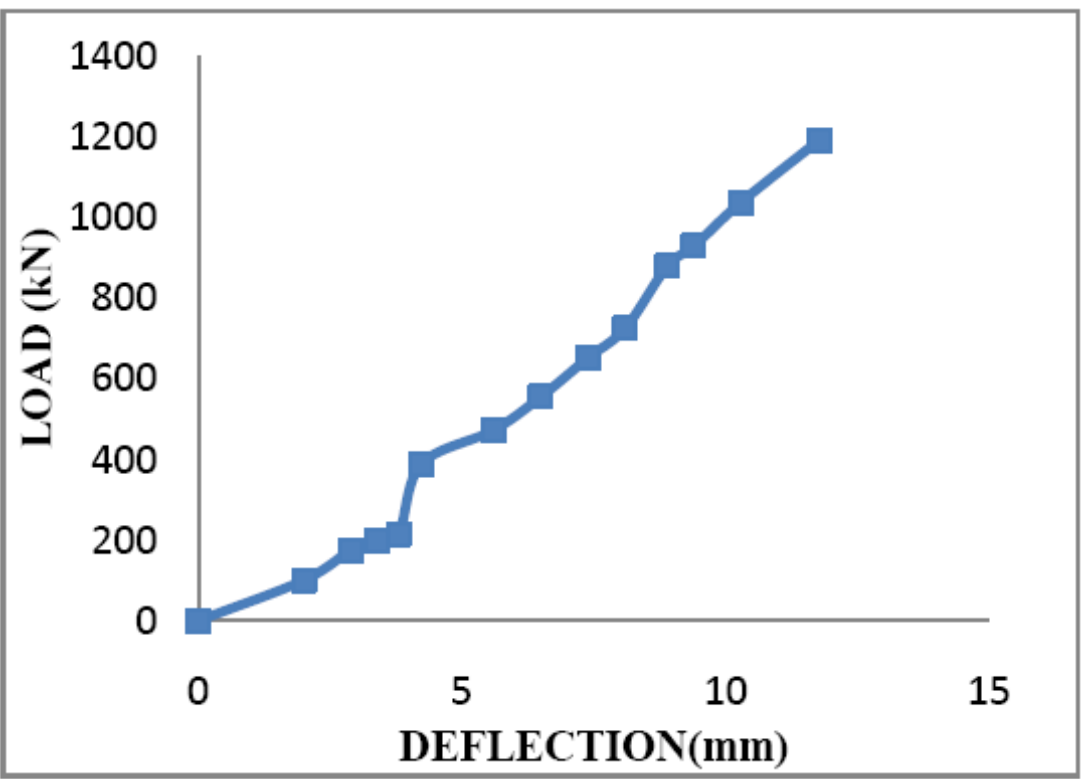

Figure19. Load Vs Deflection for Third Layer CFCT -I

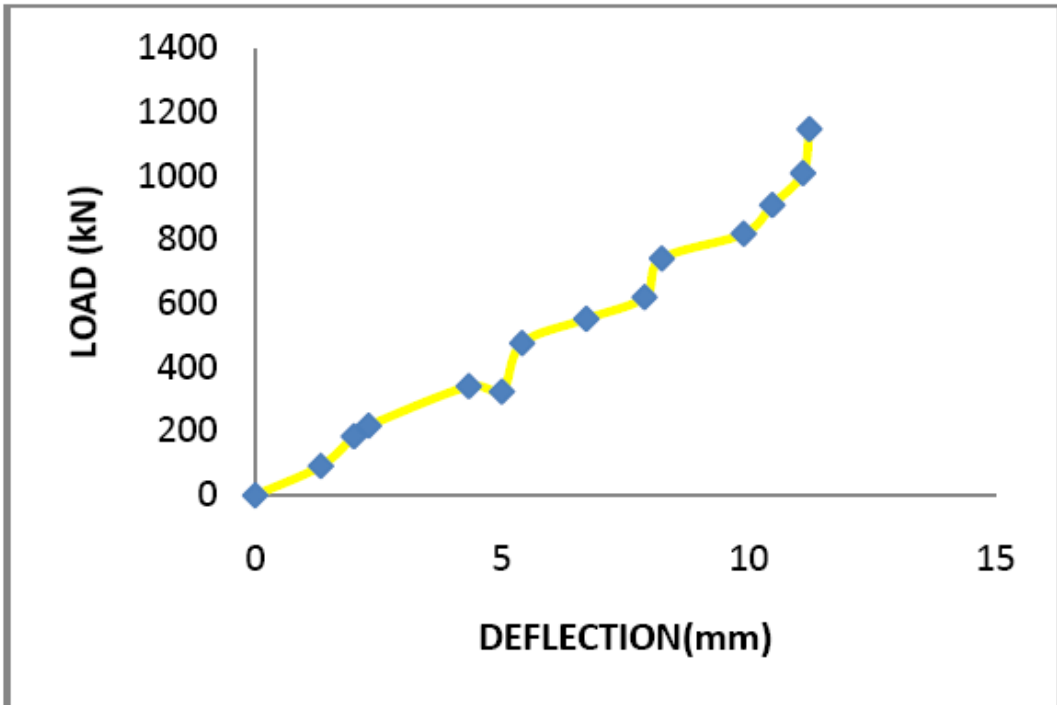

Figure20. Load Vs Deflection for Third Layer CFCT-II 


\section{CONCLUSION}

Based on the experimental investigations, the following conclusions were drawn.

1. Experimental investigation is done successfully and their results are compared.

2. From the investigation it is clearly identified that Ultimate load carrying capacity increases with increase in thickness (fiber) of the specimen.

3. The compressive strength gradually increases from $\mathrm{C} 0, \mathrm{C} 1, \mathrm{C} 2$, and $\mathrm{C} 3$ Layers with CHS tube content and increases for above average 5\%-15\% in each layer.

4. The 28 days average compressive strength obtained for $\mathrm{C} 0, \mathrm{C} 1, \mathrm{C} 2$, and $\mathrm{C} 3$ Layers with CHS tube content shows $10 \%$ to $45 \%$ increase in compressive strength when compared to control mix concrete.

5. Load carrying capacity of CFCT $3^{\text {rd }}$ LAYER \& CFCT $2{ }^{\text {nd }}$ LAYER section is increased up to $20 \%$ $50 \%$ when compared to CONTROL \& CFCT $1^{\text {st }}$ LAYER sections.

6. So it is verified that CFRP will increase the strength of the sections in normal condition and also in damaged condition.

\section{REFERENCES}

[1] IS 11269-1987 "Specification for 53 grade ordinary Portland cement.

[2] IS 383-1970 "specification for coarse and fine aggregates for natural sources for concrete.

[3] ASTM A500 Cold formed ERW round, square, rectangular structural steel tubing in grades B and $\mathrm{C}$.

[4] IS 516-1959 Methods of tests for strength of concrete.

[5] M.R. Bambach"Axial capacity and crushing behavior of metal-fiber square tubes - Steel, stainless steel and aluminum with CFRP"- NSW Injury Risk Management Research Centre, University of New South Wales, Sydney18 June 2010.

[6] G. Ganesh Prabhu, M.C. Sundarraja Behavior of concrete filled steel tubular (CFST) short columns externally reinforced using CFRP strips composite, Article in Construction and Building Materials 47:1362-1371 • October 2013.

[7] N.K. Photiou, L.C. Hollaway, M.K. Chryssanthopoulos "Strengthening of an artificially degraded steel beam utilizing a carbon/glass composite system" Construct Build Mater, 20 (2006), pp. 11-12

[8] M.C. Sundarraja, G. Ganesh Prabhu "Experimental study on CFST members strengthened by CFRP composites under compression" J Construct Steel Res, 72 (2012), pp. 75-83

[9] Suliman Abdalla, Farid Abed, Mohammad Al Hamaydeh "Behavior of CFSTs and CCFSTs under quasi-static axial compression" J Construct Steel Res, 90 (2013), pp. 235-244

[10] Patel vipulkumar Ishavarbhi "Nonlinear analysis of concrete filled steel tubular columns" Scholar's press (30 June 2015). 